\title{
HUMANIDADE E/OU TECNOLOGIA: UMA LEITURA SOBRE O FILME TRANSCENDENCE
}

\author{
CARINA ADRIELE DUARTE DE MELO FIGUEIREDO ${ }^{1}$
}

Universidade do Vale do Sapucaí

Programa de Pós-Graduação em Ciências da Linguagem

Av. Pref. Tuany Toledo, 470 - 37550-000 - Pouso Alegre (MG) - Brasil

Grupo Educacional Unis, Avenida Alzira Barra Gazzola, 650 - 37100-000 Aeroporto MG - Brasil

carinaduartemelo@gmail.com

Resumo. Este trabalho busca compreender as formulações de sentidos sobre a dicotomia tecnologia-humanidade a partir de uma análise do filme Transcendence (2014), do diretor Wally Pfister. O objetivo deste estudo é encontrar as possíveis mobilizações de sentido que se apresentam quando, a exemplo do corpus de análise, o sujeito e sua humanidade se corporificam na tecnologia. Investigar tal dicotomia pela perspectiva teórica da Análise de Discurso faz emergir a questão principal deste trabalho: quais sentidos se mobilizam quando diferentes inteligências e funções da tecnologia se fundem à humanidade do sujeito? Não responderemos a todas as possibilidades interpretativas desta questão, mas ao menos nos aventuraremos a elaborar gestos de leitura a partir da obra cinematográfica em questão.

Palavras-chave: Análise do Discurso; tecnologia; humanidade;

Transcendence.

\begin{abstract}
This work seeks to understand the formulations of meanings concerning the technology-humanity dichotomy from an analysis of the film Transcendence (2014), directed by Wally Pfister. The objective of this study was to find possible meaning mobilizations that show up when, as in the corpus of analysis, the subject and his humanity are embodied within technology. To investigate that dichotomy based on the theoretical perspectives of Discourse Analysis raises the main question of this work: what meanings are mobilized when different technological intelligences and functions merge with subject's humanity? We will not answer to all interpretative possibilities that question may lead to, but at least we will venture to elaborate reading gestures upon the cinematographic work materialized in Transcendence.
\end{abstract}

Keywords: Discourse Analysis; technology; humanity; Transcendence.

\footnotetext{
1 Doutora em Ciências da Linguagem pela Universidade do Vale do Sapucaí e Docente no curso de Licenciatura em Letras do Grupo Educacional Unis.
} 


\section{CONSIDERAÇÕES INICIAIS}

Homem: "Pode provar sua autoconsciência?"
Máquina: "Uma pergunta difícil, Sr. Tagger.
Pode provar a sua?"
Diálogo de uma cena do filme Transcendence

Prometeu, na mitologia grega, foi castigado por roubar o fogo dos deuses e dá-lo aos homens. Os deuses temiam que os humanos ficassem tão poderosos quanto eles. Prometeu, punido por toda eternidade, viu seu fígado ser devorado diariamente por uma enorme águia. Dia após dia, o fígado se regenerava e novamente a águia retornava. Essa passagem traz à tona uma memória discursiva sobre a submissão dos homens em relação aos deuses. Zeus, com receio de que os homens por meio do fogo (da técnica) se igualassem aos deuses, remete-nos a uma outra memória discursiva: de que a tecnologia pode transformar homens em deuses.

À parte da preocupação de Zeus em relação às consequências do ato de Prometeu, outras questões menos mitológicas também despertam reflexões sobre a necessidade humana de produzir artefatos e ferramentas que, de certa forma, aproximem o homem à criação. Desde sempre o ser humano esteve preocupado em dominar as técnicas capazes de desenvolver soluções para suas próprias falhas ou, até mesmo, criar extensões do seu corpo. O desenvolvimento de lentes corretivas para a melhoria da visão, as próteses, a invenção da câmera que captasse os momentos outrora perdidos e a criação de assistentes pessoais inteligentes são exemplos desta inquietante preocupação.

Este trabalho propõe discutir essas e outras discursividades tendo como objeto de análise o filme Transcendence (2014), de Wally Pfister. A obra leva o telespectador a se confrontar com diferentes hipóteses científicas e realidades virtuais de um mundo tecnológico, em que a linha divisória entre o humano e a máquina, entre a consciência e a programação, é muito tênue. Considerando a aparente similaridade do enredo da obra com uma provável realidade próxima, algumas questões vêm à tona: a tecnologia usada como ferramenta; a tecnologia usada como extensão do corpo do sujeito; o próprio sujeito caracterizado como informação e disperso na multidão de dados da rede.

Inicialmente, a apresentação do filme estende o pano de fundo que delimita este estudo. Como são diversas as possibilidades de sentidos que se atrelam à tecnologia, a contextualização do enredo da obra mostrará qual o tipo de relação entre tecnologia e humanidade de que estamos tratando. Ao mesmo tempo em que a obra é apresentada, serão explicitadas as revisões teóricas que sustentam a leitura crítica das realidades e metáforas da obra cinematográfica em questão.

Em seguida, com os aspectos teóricos relacionados às questões fundantes do filme, poderemos formular diferentes sentidos possíveis ao filme. Em conformidade com a prática analítica da Análise do Discurso, proporemos relações dessas discursividades com outras que extrapolam o filme. A partir de tais formulações possíveis, este trabalho especula sobre sentidos que permitem que a dicotomia humanidade-tecnologia seja colocada em cena. 


\title{
ASPECTOS METODOLÓGICOS
}

Como referencial teórico, elencamos alguns autores que se destacam na discussão sobre tecnologia dentro das ciências da linguagem. Para analisarmos o sujeito digital dentro da perspectiva discursiva, selecionamos os estudos de Cristiane Dias, em Sujeito Digital: sentidos de um novo paradigma (2013). A fim de compreendermos o empoderamento humano a partir do uso de aparatos tecnológicos, recorremos às considerações sobre o deus protético, formuladas por Freud em $O$ mal-estar na civilização (2011). Também traremos para discussão Linguagens líquidas na era da mobilidade (2007), de Lucia Santaella, e $O$ império Cibernético (2004), de Céline Lafontaine.

De acordo com os referenciais teóricos citados e tendo como fundamentação teórico-metodológica da pesquisa o método qualitativo-interpretativista, este estudo propõe pensar nas possíveis formulações de sentido a partir do filme Transcendence. Busca-se compreender como são mobilizados alguns dos possíveis sentidos depreendidos da relação humanidade e tecnologia - dicotomia bastante evidenciada na obra cinematográfica em questão.

\section{APRESENTAÇÃO DO CORPUS E REVISÕES TEÓRICAS}

No filme, Will Caster, um renomado cientista que se destaca por suas pesquisas sobre Inteligência Artificial, desenvolve uma máquina autoconsciente. Como o tema se confronta com questões morais e éticas, o personagem Will é perseguido pelo grupo nomeado "anti-tecnologia". Nas cenas iniciais, Caster discursa em uma palestra.

\begin{abstract}
Minha esposa sempre quis mudar o mundo, mas eu só gostaria de entendê-lo primeiro. Por 130 mil anos nossa capacidade de raciocínio permaneceu a mesma. Se juntarmos as mentes dos neurocientistas, engenheiros, matemáticos e hackers neste auditório, não chegaremos nem perto da inteligência artificial mais básica. Uma vez on-line, uma máquina consciente ultrapassa as limitações biológicas, em pouco tempo sua capacidade analítica vai ser maior do que a inteligência coletiva de todo ser humano já nascido na história do mundo. Agora imaginem essa máquina com todas as emoções humanas, inclusive autoconsciência. Alguns cientistas chamam de isso de singularidade, eu chamo de transcendência. $O$ caminho para construir essa superinteligência exige que desvendemos os segredos mais fundamentais do universo: qual é a natureza da consciência? Almas existem? Se existem, onde residem? (TRANSCENDENCE, 2014)
\end{abstract}

Logo após discursar, o personagem Will é baleado pelos extremistas "antitecnologias". A bala infectada leva o cientista a "quase" morte - quase porque, antes de o corpo se degenerar, sua esposa Evelyn e o pesquisador Max Waters, que é também melhor amigo de Caster, conseguem transpor a sua "consciência" para a máquina. Will é uploadeado para um computador. Tudo que precisará para manter-se "vivo" é estar conectado.

A história se desenrolará a partir de três tramas: 1. A história amorosa de Will e Evelyn; 2. A relação com o amigo Max - um cientista com visões mais humanistas; 3. Os conflitos com os "anti-tecnologias". 
O filme possibilita problematizações como: é possível uma máquina ter autoconsciência? Quais as consequências desse poder sobre-humano em que, estando online, tudo vê e tudo acessa? Tendo se tornado onipresente, Will se iguala a Deus? A máquina com autoconsciência seria, de fato, Will? O que define o homem como homem: o corpo ou a consciência? Se há a transposição da consciência para a máquina, pode-se considerar ainda a existência do humano? As formulações dessas questões nos permitem ainda indagar: quais condições possibilitam que tais sentidos - como desenvolvimento da ciência, considerações filosóficas sobre o que é a consciência etc. - sejam postos em cena? Importa menos responder as perguntas do que compreender os sentidos que elas mobilizam. Consideremos, inicialmente, o seguinte diálogo.

- Dr. Caster, então você quer criar um Deus? Seu próprio Deus?

- Excelente pergunta. Não é isso que o homem sempre fez? (TRANSCENDENCE, 2014).

Voltando à proposta deste trabalho, notamos que o diálogo anterior nos remete à ideia de que, por meio da tecnologia, os homens poderiam se igualar a Deus. Estando online, Will torna-se onipotente, onipresente $\mathrm{e}$ onisciente - e assim atinge a tal "transcendência".

Lucia Santaella, em Linguagens líquidas na era da mobilidade (2007), discorre sobre a rematerialização do sujeito no universo virtual. Suas colocações contribuem para que compreendamos a noção de "transcendência" formulada no filme.

[...] o sujeito já não está localizado em um tempo/espaço estável, em um ponto de vista fixo do qual possa calcular racionalmente suas opções. Pelo contrário, ele está multiplicado em bancos de dados, dispersado entre mensagens eletrônicas, descontextualizado e reindentificado em comerciais de $\mathrm{TV}$, dissolvido e rematerializado continuamente em algum ponto na incessante transmissão e recepção eletrônicas de símbolos. Isso nos leva a sublinhar que o surgimento da cibercultura tornou o Outro (o grande outro da psicanálise, o lugar da linguagem, dos códigos, da cultura) mais complexo. Não deve ser por acaso que muitos 'plugados' apresentam o sentimento irresistível de colocar o ciberespaço em algum ponto muito próximo da ideia de Deus, pois Deus continua sendo a manifestação mais perfeita e legítima do Outro. (SANTAELLA, 2007, p. 97)

Através da concepção de sujeito onipresente, os sentidos de espaço e tempo deslizam-se e requerem reformulações. A própria ideia de liquidez e pós-humano - tão explorada e difundida por escritores com Zygmunt Bauman e como própria Lucia Santaella aqui no Brasil - amplia nossa leitura sobre esses deslizamentos de conceitos/formulações de sentido: "já não há lugar, nenhum ponto de gravidade de antemão garantido para qualquer linguagem, pois todas entram na dança das instabilidades" (SANTAELLA, 2007, p. 24).

Aqui transcendência e pós-humano podem ser colocados lado a lado, pois Will só atinge a transcendência quando vai para além do humano, ou seja, quando alcança o estágio pós-humano. A fim de que compreendamos um pouco mais sobre a transcendência em comparação ao pós-humano, vejamos os sentidos vinculados à expressão "pós-humano" formulados por Santaella. 
[...] Foi justamente no terreno sedimentado por esse tipo de ficção e pelas inquietações e indagações nela presentes que a expressão "póshumano" gradativamente tomou corpo. Conforme já indiquei em outra ocasião (SANTAELLA, 2003, p. 191), expressões similares, tais como "autômata bioinformático", "biomaquinal", "pós-biológico", foram aparecendo cada vez mais assiduamente em publicações de arte e cultura cibernéticas até que, em meados dos anos 1990, todas elas consolidaram-se no caldo da cibercultura emergente. O sema comum que as une encontra-se no hibridismo do humano com algo maquínicoinformático, que estende o humano para além de si. Assim, a condição pós-humana diz respeito à natureza da virtualidade, genética, vida inorgânica, ciborgues, inteligência distribuída, incorporando biologia, engenharia e sistemas de informação. Por isso mesmo, os significados mais evidentes, que são costumeiramente associados à expressão "póshumano", unem-se às inquietações acerca do destino biônico do corpo humano. (SANTAELLA, 2007, p. 129)

Retornando ao filme, não é só pela transcendência que Will parece se igualar a Deus. Quando o personagem começa a desenvolver o seu projeto de "curar o mundo" por meio da tecnologia, podemos notar uma outra espécie de Deus - o deus protético, semelhante ao anunciado por Freud.

Se voltarmos suficientemente atrás no tempo, os primeiros atos culturais foram o uso de instrumentos, o domínio sobre o fogo, a construção de moradias. Entre eles sobressai o domínio do fogo, realização extraordinária e sem precedente; com os outros animais iniciou caminhos que desde então nunca deixou de seguir, e cujo estímulo primordial não é difícil imaginar. Com todos os seus instrumentos ele aperfeiçoa os seus órgãos - tanto motores como sensoriais - ou elimina os obstáculos para desempenho deles. Os motores lhe colocam à disposição imensas energias, que tal como seus músculos ele pode empregar em qualquer direção; os navios e os aviões não deixam que a água e o ar lhe impeçam a movimentação. Com os óculos ele corrige as falhas de lente de seu olho, com o telescópio enxerga a enormes distâncias, com a câmera fotográfica ele criou um instrumento que guarda as fugidias impressões visuais, o que o disco de gramofone também faz com as igualmente transitórias impressões sonora; no fundo, os dois são materializações da sua faculdade de lembrar, de sua memória. [...] O ser humano tornou-se, por assim dizer, uma espécie de deus protético, realmente admirável quando coloca todos os seus órgãos auxiliares; mas estes não cresceram com ele e ocasionalmente lhe dão ainda muito trabalho. (FREUD, 2011, p. 35-36)

$\mathrm{Na}$ busca pela imortalidade, o homem usa a tecnologia como extensão do seu corpo. Até mesmo a inserção de informações nos bancos de dados e/ou nas redes sociais podem denotar o desejo de se igualar a Deus, visto que onipresença e imortalidade são comumente tomados como atributos divinos. Os sentidos de transcendência e póshumano formulados até aqui se aproximam em certa perspectiva ao que Freud categorizou como "deus protético" e também à "outra espécie de corpo", como nomeou Santaella:

[...] nossos corpos são agora feitos de máquinas, imagens e informações. Os corpos vivos estão borrados, moldados e transformados pela tecnologia e a cultura está tomando conta da biosfera. Do mesmo modo, Hayles (1996, p. 12) considera que o póshumano representa a construção do corpo como parte de um circuito 
integrado de informação e matéria que inclui componentes humanos e não-humanos, tanto chips de silício quanto tecidos orgânicos, bits de informação e bits de carne e osso. Um tal recorte semântico, pressagiando o futuro de uma outra espécie de corpo, nas interfaces do humano e do maquínico, é aquele que, sem dúvida, tem dominado no entendimento do pós-humano. (SANTAELLA, 2007, p. 130)

Discussões recentes vão além com um discurso mais ousado: "o corpo como extensão da máquina" e não a "máquina como extensão do corpo". Cristiane Dias, em seu artigo Sujeito digital: sentidos de um novo paradigma (2013), analisa essa relação inversa, o modo como o discurso sobre as tecnologias individua o sujeito. A autora percorre "pela via dos dispositivos móveis que habitam nosso cotidiano para mostrar esses efeitos no nível molecular" (DIAS, 2013, p. 55). Sua primeira análise é sobre a publicidade do jogo Xbox 360 com Kinect: "o jogador é o próprio controle: 'You are the controller', como formulado no vídeo da publicidade. O sujeito-jogador se torna, assim, um periférico da máquina, uma extensão da máquina” (DIAS, 2013, p. 56).

Tais colocações nos permitem elaborar analogias com o filme: quando o personagem Will começa a ditar as regras por trás do computador (ou sendo o próprio computador), o que vemos é o humano como extensão da máquina, como um obediente fantoche. Em diversas cenas, o mundo on-line sugere mais concretude e efeito de real do que o universo dos homens enquanto "libras de carne". Hoje, em vários setores, as transações on-line já são consideradas mais fidedignas do que o tête-à-tête: por exemplo, em alguns hotéis são aceitas apenas as reservas realizadas através da internet; nas solicitações de adesões/cancelamentos em empresas, embora a pessoa esteja presente, é comum ouvir "envie em e-mail formalizando o pedido".

A internet móvel nos permite cada vez mais acessar, de qualquer lugar, televisão, rádio, e-mail, MSN, sites, serviços públicos, até mesmo realizar transações bancárias. Hoje, com a internet é possível clicar sobre ícones e nos movermos de um lugar a outro. (DIAS, 2013, p. 16)

A rede de internet que nos multiplica em inúmeros dados, diversos como as plataformas que os divulgam, é a mesma que, a cada inovação, se faz mais segura, confiável e flexível às principais transações dos usuários. No filme, a naturalidade de uma sociedade com elevado avanço na tecnologia, embora ainda um pouco distante de nós no tempo, não faz o telespectador duvidar de que ela venha, talvez em breve, a existir dessa maneira. E é para essas inúmeras possibilidades discursivas que o filme aponta que procuraremos, na próxima seção, analisar algumas possíveis formulações de sentido, tal como elas são produzidas no filme.

\section{AS FORMULAÇÕES DE SENTIDO EM TRANSCENDENCE}

Há tempos, é comum encontrar discussões sobre quem (ou qual) detém a primazia: tecnologia versus humanidade. A fim de ampliarmos a reflexão sobre as disputas que podem aí se instalar, propomos aqui três formulações.

1. Humanidade $e$ Tecnologia

2. Humanidade ou Tecnologia.

3. Humanidade e/ou Tecnologia. 
O uso do e/ou como possibilidade de mobilizar os dois conceitos como aditivos ou alternantes: humano e máquina (juntos), como sugerem os projetos de ciborgues; ou ainda: humano ou máquina, coexistindo, mas não se confundindo/mesclando. Se pensarmos que o humano perdeu há tempos sua natureza, logo não há nada mais humano que a tecnologia. Essa interpretação (outra) permite rescindir a dicotomia humanidade versus tecnologia.

Provocações e hesitações ocorrerão em diversas passagens do filme. $\mathrm{O}$ que define o homem enquanto homem? Sua materialidade? A consciência? Ou seria sua alma? como ironiza Will em uma das primeiras cenas. Se Will transpassa do corpo (humano) para a máquina, Will deixa de ser Will? Sabemos que a troca da matéria nos leva a uma nova relação de sentido, outra discursividade.

A busca da exteriorização do corpo não é algo novo, ela sempre existiu oriunda do desejo de imortalidade, mas sempre ocorreu como uma projeção, seja a projeção da vida num tempo/espaço futuros, como a crença da vida eterna no paraíso, por exemplo. Trata-se de uma exteriorização virtual do corpo. Hoje, contudo, essa exteriorização se materializa, se torna, além de virtual, visual, material, concreta. Tratase dos seres híbridos, das memórias metálicas e digitais, das próteses e cirurgias, dos avatares, robôs e corpos-escaneados, impressos, corpos estendidos, do mundo contemporâneo, levados a assumir uma forma exterior a si de modo que "nós não vemos tecnologia, vemos pessoas". (DIAS, 2013, p. 63)

Os próprios cartazes de divulgação do filme trabalham com essa dualidade.

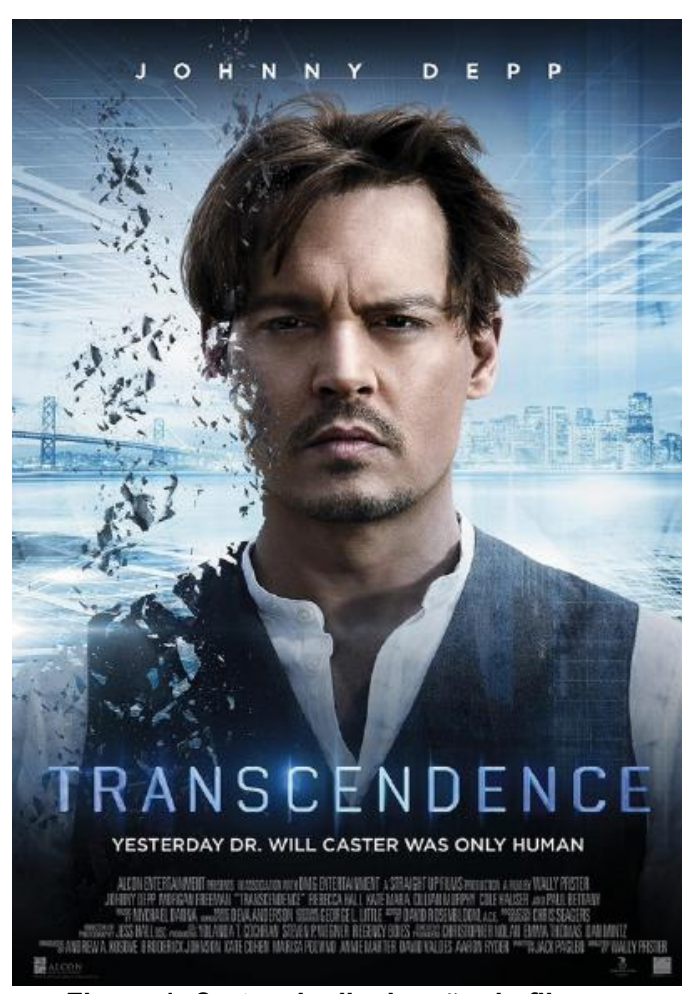

Figura 1. Cartaz de divulgação do filme. 


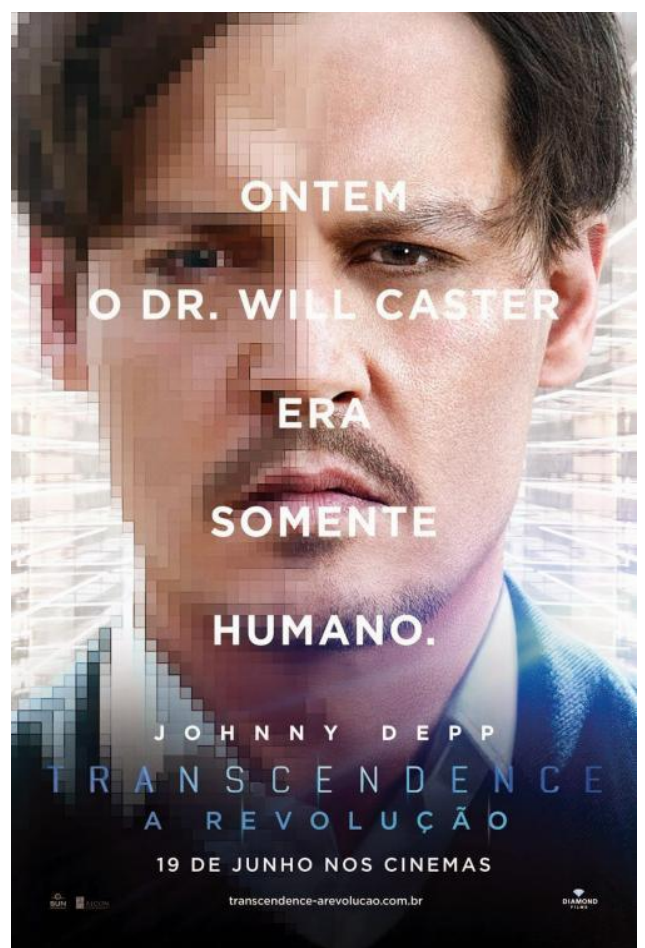

Figura 2. Cartaz de divulgação do filme.

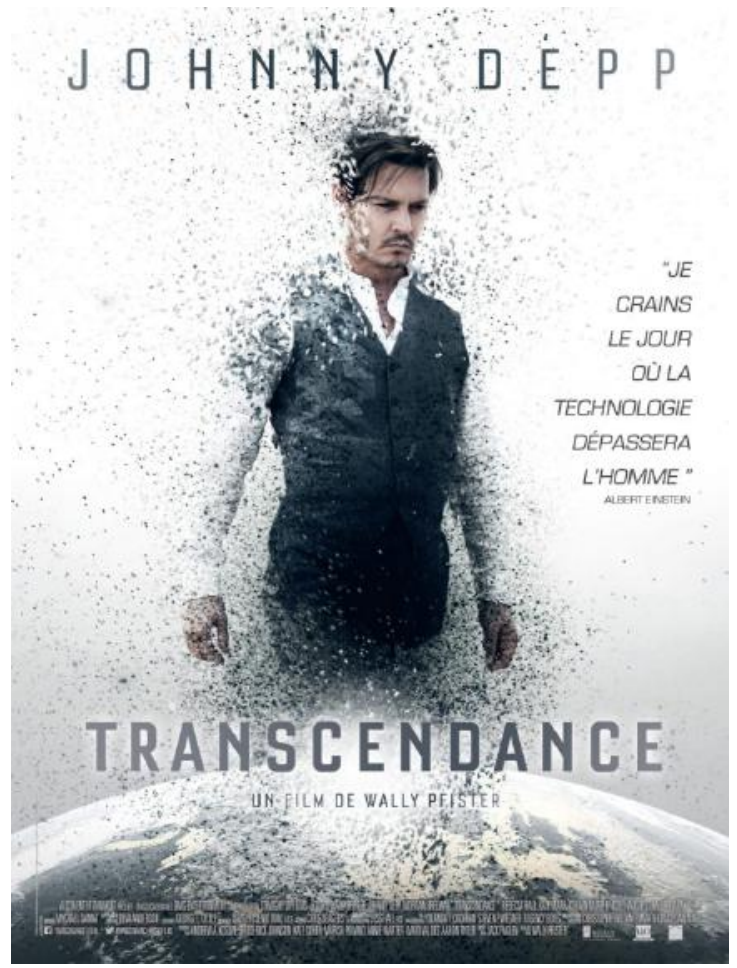

Figura 3. Cartaz de divulgação do filme.

A primeira e a terceira imagens (figs. 1 e 3) mostram o homem que se desintegra. Novamente, somos conduzidos à ideia de onipresença: desintegra-se para estar em todos os lugares, desintegra-se para se tornar virtual(izado). Já na segunda imagem, há o sentido 
mais claro de "homem e máquina" (concomitantes), sendo a máquina representada pela metade da imagem em pixels.

Os enunciados também chamam atenção: "ontem o Dr. Will Caster era somente humano", por exemplo. Em um sentido mais pejorativo, o advérbio somente alude à ideia de que algo pode ser acrescentado, somado e, por outro lado, também remete ao sentido de limitação: se ontem ele era apenas um humano, hoje ele é mais, mais porque ele tornou-se máquina. Logo, traz à tona a formulação da humanidade sob a tecnologia. $\mathrm{Na}$ figura 3, o enunciado "je crains le jour où la technologie dépassera l'homme" também coloca a primazia da tecnologia em relação à humanidade, no entanto, o verbo temer faz referência ao receio de que a tecnologia domine o homem, discurso muito presente no filme pelos personagens considerados extremistas - os ditos "anti-tecnologias". Vale considerar que

o que aprisiona o sujeito e o i-mobiliza perante a sociedade são seus inventos. Não no sentido de que sejam benéficos ou maléficos, mas no sentido de que eles determinam a forma material da sociedade, os modos de vida dos sujeitos, sua posição na sociedade, as "coisas-asaber", sua circulação e formulação. (DIAS, 2011, p. 22)

Vemos ecoar sintomas de Transcendence na sociedade ${ }^{3}$. Interessa-nos analisar tais sinais a partir do modo como o discurso sobre Inteligência Artificial (IA) tem sido veiculado. Vejamos o exemplo em que o repórter Hamlet Kim cita parte do relatório de cientistas no The Independent.

A pesquisa sobre a Inteligência Artificial (IA) está progredindo rapidamente. Marcos recentes, como os carros que dirigem sozinhos, um computador ganhar um show de perguntas e respostas, e os assistentes pessoais digitais Siri, Google Now e Cortana são apenas sintomas de uma corrida armamentista de TI sem precedentes, alimentada por investimentos e o fortalecimento de uma base teórica cada vez mais madura. Tais conquistas, provavelmente, não serão nada perto do que as próximas décadas vão trazer. (KIM, 2014, n.p.)

Na maior parte das vezes, as notícias sobre IA anulam a ação do homem: carros que dirigem sozinhos, computadores que "advinham" as perguntas pensadas pelos humanos. Há o discurso de que não existe o homem por detrás das máquinas. É esse apagamento do homem forjado no modo como o discurso é produzido que faz com que dicotomias sejam forjadas: de um lado, os que temem um mundo em que as máquinas dominem e que os homens passem a ser secundários, submissos a tecnologias por eles inventadas; de outro lado, o sonho de um Tomorrowland - um lugar onde tudo pode acontecer: o mundo pode ser curado por nanotecnologias, é possível estarmos em todos os lugares, não existem mais distâncias e nem problemas que não possam ser corrigidos por artefatos (lógica do consumo), suspensão de qualquer interdição. A ideia que permite que tudo seja possível é uma união dos discursos da ciência e do capitalismo. Esses inventos, como sugere Dias (2011), determinam os modos de vida dos sujeitos, sobretudo, devido à forma como esses sentidos passam a circular e a serem formulados. A forma material condiciona os modos de subjetivação. Nessa direção, "adivinhar" e "inventar" podem ser colocados aqui em uma relação parafrástica.

\footnotetext{
2 Tradução: Eu tenho medo do dia em que a tecnologia superará o homem.

${ }^{3}$ Compreende-se "sintoma" como indício, sinal de algo.
} 
1. Computadores adivinham sozinhos as perguntas.

2. Computadores inventam sozinhos as perguntas.

Tanto em "adivinhar" como em "inventar", a figura humana é deixada em segundo plano.

No início do mês de julho de 2015, foi veiculada em diferentes mídias a notícia de que um homem havia sido morto por um robô em uma das fábricas da Volkswagen. Alguns sites ainda foram mais sensacionalistas ao anunciar uma rebelião das máquinas. Seguem exemplos.

\title{
Robố mata funcionário da Volkswagen na Alemanha Acidente aconteceu depois que um técnico acessou a gaiola de proteção do robô
}

\author{
BRUNO FERRARI \\ 01/O7/2015 - 16h04 - Atualizado 01/07/2015 17h38
}

\begin{tabular}{|c|c|c|c|c|}
\hline f Compartinar $(5576)$ & P pinar & In comp. & 8. comp. & 2 Tuttar \\
\hline
\end{tabular}

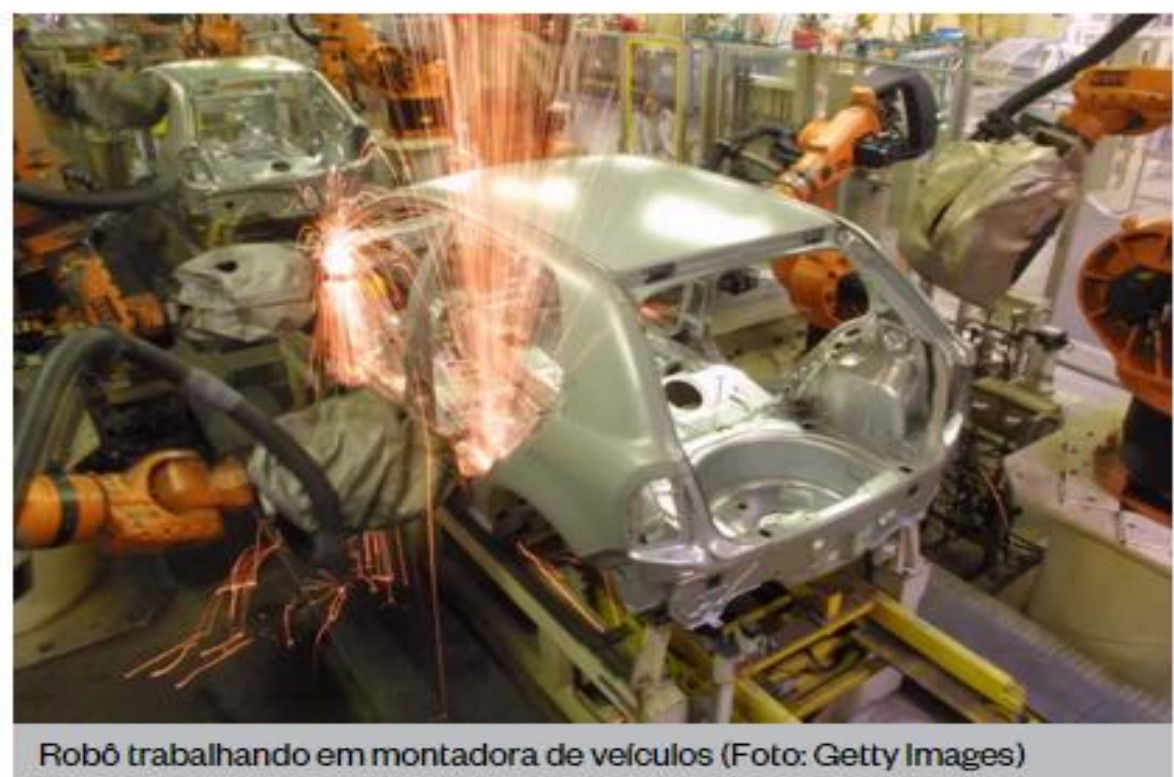

Figura 4. Notícia da Revista Época. Disponível em http:/lepoca.globo.com/vida/experienciasdigitais/noticia/2015/07/robo-mata-funcionario-da-volkswagen-na-alemanh.html. Acesso em 12 nov. 2015. 
01/07/201521h18 - Atualizado em 01/07/201521h25

\section{Robô agarra e mata trabalhador dentro de fábrica da Volkswagen}

Caso aconteceu nesta segunda-feira (29) em planta situada na Alemanha. Autoridades investigam se há quem culpar pela morte.

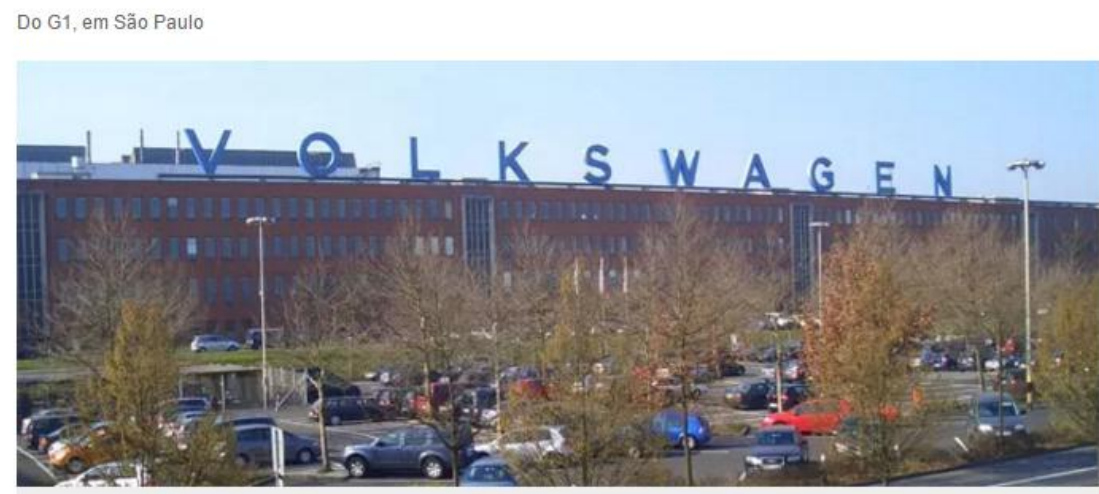

Fábrica da Volkswagen em Baunatal (Foto: Feuermond16/Creative Commns)

Figura 5. Notícia do G1. Disponível em http://g1.globo.com/mundo/noticia/2015/07/robo-agarra-emata-trabalhador-dentro-de-fabrica-da-volkswagen.html. Acesso em 12 nov. 2015.

\section{Trabalhador é morto por robô em fábrica da Volkswagen na Alemanha}

CHRIS BRYANT

RICHARD WATERS

DO "FINANCIAL TIMES"

DE SÃO PAULO

$02 / 07 / 2015 \odot 12 h 02$

f Compartilhar $\rightarrow g^{+}$in $\left.\nabla<1,0 \mathrm{mil} \quad-(1)\right)$ ouvir o texto $\quad+$ Mais opçöes

Um técnico foi morto por um robô em uma fábrica da Volkswagen perto de Kassel, Alemanha, na quartafeira (1), em um raro acidente que traz à tona preocupações com a expansão da automação e seu impacto sobre o emprego.

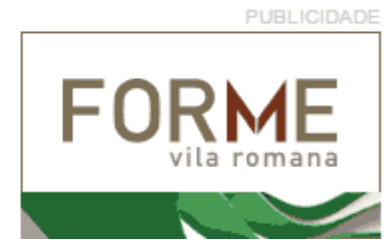

Figura 6. Notícia da Folha de São Paulo. Disponível em http://www1.folha.uol.com.br/mercado/2015/07/1650682-trabalhador-e-morto-por-robo-em-fabricada-volkswagen-na-alemanha.shtml. Acesso em 12 nov. 2015. 
A partir dos recortes sobre as referidas notícias, podemos considerar três formulações discursivas produzindo diferentes sentidos.

1. Robô mata funcionário da Volkswagen na Alemanha [...] Robô trabalhando em montadora de veículos.

2. Robô agarra e mata trabalhador dentro de fábrica da Volkswagen [...] Autoridades investigam se há quem culpar pela morte.

3. Trabalhador é morto por robô em fábrica da Volkswagen na Alemanha.

Tanto na primeira quanto na segunda formulação, o Robô aparece como sujeito na voz ativa seguido de verbos de ação comumente atribuídos a atividades humanas: agarrar, matar, trabalhar. Na segunda, há ainda a hesitação sobre quem culpar, seria possível culpar um robô? Um robô poderia ser julgado como um humano? Novamente fica sugerida a dicotomia humanidade e/ou tecnologia. Na terceira notícia, embora o enunciado seja construído na voz passiva (o robô sai da condição de sujeito ativo e vai para a condição de agente da passiva), muda-se a estrutura oracional, mas, o sentido continua próximo: robô como agente. Tanto a estrutura sintática quanto a carga semântica dos verbos (agarrar/matar) intensificam um lado agressivo atribuído ao robô, enfatizando ainda mais a ideia de os robôs significarem possível ameaça aos humanos.

No entanto, o que nenhum dos sites citados ressaltou é que o incidente foi causado por um erro humano e que não se tratava de uma briga entre homem e robô. O acidente ocorreu quando o trabalhador estava configurando a máquina, que é utilizada para construir motores elétricos dos carros da Volkswagen.

É certo que o pós-humano, tal como o seu primo chegado, o ciborgue, é uma criatura metafórica. Só que a metáfora toma agora corpo nos laboratórios da engenharia genética. Para o constatar, basta lançar um breve olhar sobre as crónicas científicas que povoam a imprensa quotidiana. Robôs humanizados em seres vivos informatizados, próteses electrónicas num ser humano transgénico, xenotransplantes na área da clonagem, cada dia que passa traz consigo o seu lote de experiências realizadas pelos Frankensteins da tecnociência. Longe de estar confinado ao imaginário da ficção científica, o ser pós-humano bate à porta do nosso mundo transfronteiriço, onde o real e o virtual se confundem. (LAFONTAINE, 2004, p. 178)

Os sentidos vinculados a essa não distinção entre homens e máquinas resulta do próprio conceito de cibernética. Lafontaine, no texto $O$ ser pós-humano, último elo da evolução?, ao trazer para cena o nascimento da cibernética, retoma a entrada da física no terreno da biologia e os impactos dessa interdisciplinaridade na definição de vida: "a cibernética [...] efectiva a passagem da física para a biologia, anulando qualquer distinção entre o vivo e o não vivo" (LAFONTAINE, 2004, p. 180). A autora faz ainda um levantamento de pesquisas que mostraram uma concepção puramente informacional dos seres vivos ao utilizarem o modelo do código genético para descrever o modo de transmissão da hereditariedade. Colocando lado a lado os programas genético e informático, a autora dirá que "[...] programa genético organiza e controla o desenvolvimento dos seres vivos da mesma maneira que o programa informático comanda as operações efectuadas por um computador" (LAFONTAINE, 2004, p. 185). Ao equiparar o código da "vida" a processos informáticos, a fronteira entre o humano e não-humano fica ainda mais movediça. 
Não restam dúvidas de que todos são afetados pela discursividade que produz como evidência a dicotomia "humanidade versus tecnologia", mas, como sabemos, não existem discursos politicamente neutros, todos são carregados de sentidos que se deslocam, sentidos que podem vir a ser outros.

Um mundo sem fronteiras, inteiramente voltado à comunicação e à troca de informações, no seio do qual as barreiras entre o ser humano, o animal e a máquina parecem estar definitivamente abolidas. [...] Um mundo povoado de seres híbridos, como as máquinas inteligentes, os robôs e os ciborgues, cujos feitos são anunciados todos os dias pelos meios de comunicação social. Em suma, um mundo melhor, no qual o humano pode, por fim, ter a esperança de chegar pela via da técnica à imortalidade. (LAFONTAINE, 2004, p. 15)

Os sentidos que se modificam engendram outros sentidos que, a depender da rápida evolução da tecnologia e da imersão do homem nela, podem ser associados a processos de formulação de tantos outros (novos) sentidos. Nesse processo, produz-se como fato a crescente capacidade humana de se aproximar da imortalidade, o que pode também deslocar-se na medida em que homem e máquina já constituam matéria única.

\section{CONSIDERAÇÕES FINAIS}

Narrativas cinematográficas também são formulações de sentido em um dado momento histórico. Por mais que vejamos pesquisas (e muitas) sobre Inteligência Artificial, imaginar o deslocamento da "consciência" para a máquina como é apresentado em Transcendence nos parece distante e utópico - até mesmo porque o conceito de "consciência" é bastante opaco e pode ser levado/usado/mobilizado filiando-se a diferentes formações discursivas.

Interessou-nos, neste trabalho, não temer o futuro ou tomar juízos de valor, mas, ao menos, tentar analisar como esses sentidos são produzidos e veiculados forjando uma evidência história para certa forma comportamental dos homens. Seja no discurso sobre tecnologia, ou no discurso religioso, ou ainda no discurso das artes, em todos eles notamos rastros da tentativa de o homem driblar a morte. Se para Prometeu a imortalidade lhe parece uma condenação, para os homens ela vem como possibilidade de redenção, "transcendência".

\section{REFERÊNCIAS}

DIAS, Cristiane. Sujeito digital: sentidos de um novo paradigma. Em: GUIMARÃES, Eduardo (ORG). Cidade, Linguagem e Tecnologia: 20 anos de história. Campinas, LABEURB, 2013. . e-Urbano: a forma material do eletrônico no urbano. Em: DIAS, Cristiane. E-urbano: sentidos do espaço urbano/digital. Campinas, 2011. E-book Disponível em: https://www.labeurb.unicamp.br/livroEurbano/pdf/eurbano2.pdf. Acesso em 5 jun. 2015.

FREUD, Sigmund. O mal-estar na civilização. São Paulo: Penguin Classics; Companhia das Letras, 2011.

KIM, H. Stephen Hawking alerta dos riscos da Inteligência Artificial, ao abordar novo filme de Johnny Depp. Disponível em: http://portugues.christianpost.com/news/stephen-hawking-alertados-riscos-da-inteligencia-artificial-ao-abordar-novo-filme-de-johnny-depp-19455/. Acesso em 7 jun. 2015. 
LAFONTAINE, C. O império cibernético. Trad. Port. Lisboa: Instituto Piaget, 2004.

SANTAELLA, Lucia. Linguagens líquidas na era da mobilidade. São Paulo: Paulus, 2007. . Pós-humano - Por quê? REVISTA USP, São Paulo, n.74, 126-137, junho/agosto 2007.

TRANSCENDENCE. Direção: Wally Pfister. Alcon Entertainment; Straight Up Films, 2014. 1 DVD (119 min).

TRANSCENDENCE. Cartazes de divulgação do filme. Disponíveis em: (1) http://subscene. com/subtitles/ transcendence. Acesso em 5 jun. 2015. (2) Figura 2. Disponível em: http://www. ccine10.com.br/transcendence-a-revolucao-critica/. Acesso em 5 jun. 2015. (3) Figura 3. Disponível em: http://ilovefilmesonline.com /2014/06/transcendence-revolucao-filmeonline.html. Acesso em 5 jun. 2015.

Artigo recebido em: maio de 2018.

Aprovado e revisado em: setembro de 2018.

Publicado em: dezembro de 2018.

Para citar este texto:

FIGUEIREDO, Carina Adriele Duarte de Melo. Humanidade e/ou tecnologia: uma leitura sobre o filme Transcendence. Entremeios [Revista de Estudos do Discurso, ISSN 2179-3514, on-line, www.entremeios.inf.br], Seção Estudos, Programa de Pós-Graduação em Ciências da Linguagem (PPGCL), Universidade do Vale do Sapucaí (UNIVÁS), Pouso Alegre (MG), vol. 17, p. 77-90, jul. - dez. 2018.

DOI: http://dx.doi.org/10.20337/ISSN2179-3514revistaENTREMEIOSvol17pagina77a90 